This item was submitted to Loughborough's Research Repository by the author.

Items in Figshare are protected by copyright, with all rights reserved, unless otherwise indicated.

\title{
Laminar flamelet model prediction of NOx formation in a turbulent bluff-body combustor
}

PLEASE CITE THE PUBLISHED VERSION

PUBLISHER

Professional Engineering Publishing / @ IMechE

VERSION

VoR (Version of Record)

LICENCE

CC BY-NC-ND 4.0

\section{REPOSITORY RECORD}

Venkata, Satyanarayana M. Ravikanti Veera, Mamdud Hossain, and W. Malalasekera. 2019. "Laminar Flamelet Model Prediction of Nox Formation in a Turbulent Bluff-body Combustor". figshare.

https://hdl.handle.net/2134/5534. 
This item was submitted to Loughborough's Institutional Repository (https://dspace.lboro.ac.uk/) by the author and is made available under the following Creative Commons Licence conditions.

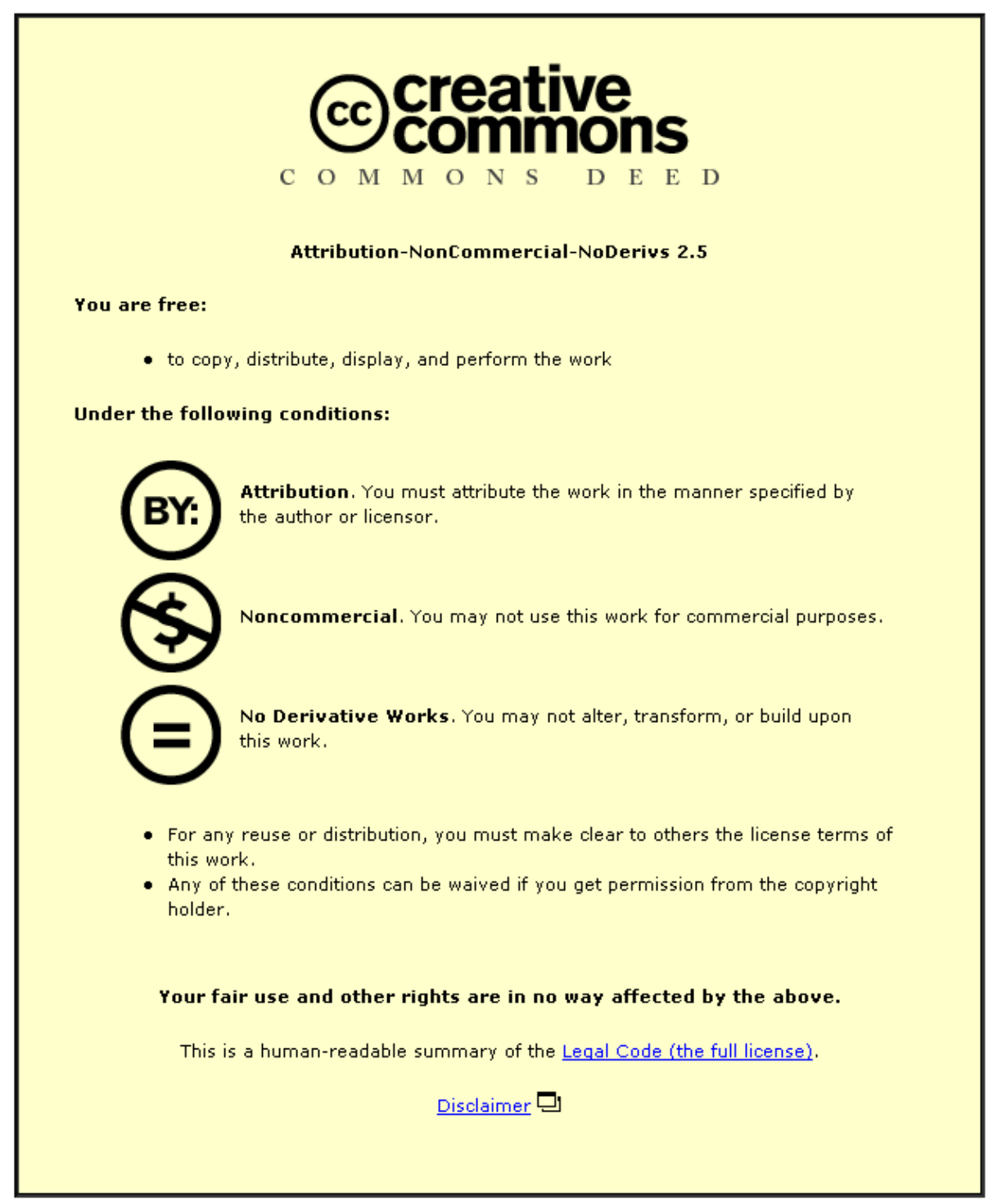

For the full text of this licence, please go to: http://creativecommons.org/licenses/by-nc-nd/2.5/ 


\title{
Laminar flamelet model prediction of $\mathrm{NO}_{x}$ formation in a turbulent bluff-body combustor
}

\author{
M Ravikanti ${ }^{1}$, M Hossain ${ }^{2 *}$, and W Malalasekera ${ }^{1}$ \\ ${ }^{1}$ Wolfson School of Mechanical and Manufacturing Engineering, Loughborough University, Loughborough, \\ Leicestershire, UK \\ ${ }^{2}$ School of Engineering, The Robert Gordon University, Schoolhill, Aberdeen, Aberdeenshire, UK
}

The manuscript was received on 18 December 2007 and was accepted after revision for publication on 22 September 2008.

DOI: 10.1243/09576509JPE569

\begin{abstract}
A bluff-body combustor, with recirculation zone and simple boundary conditions, is ideal as a compromise for an industrial combustor for validating combustion models. This combustor, however, has proved to be very challenging to the combustion modellers in a number of previous studies. In the present study, an improved prediction has been reported through better representation of turbulence effect by Reynolds stress transport model and extended upstream computational domain. Thermo-chemical properties of the flame have been represented by a laminar flamelet model. A comparison among reduced chemical kinetic mechanism of Peters and detailed mechanisms of GRI 2.11, GRI 3.0, and San Diego has been studied under the laminar flamelet modelling framework. Computed results have been compared against the well-known experimental data of Sydney University bluff-body $\mathrm{CH}_{4} / \mathrm{H}_{2}$ flame. Results show that the laminar flamelet model yields very good agreement with measurements for temperature and major species with all the reaction mechanisms. The GRI 2.11 performs better than the other reaction mechanisms in predicting minor species such as $\mathrm{OH}$ and pollutant NO. The agreement achieved for $\mathrm{NO}$ is particularly encouraging considering the simplified modelling formulation utilized for the kinetically controlled NO formation.
\end{abstract}

Keywords: bluff-body, combustion, laminar flamelet, $\mathrm{NO}_{x}$ prediction

\section{INTRODUCTION}

Fundamental understanding of the combustion process is of paramount importance not only for achieving better thermal efficiency but also for reducing pollutant emissions. Nitrogen oxides $\left(\mathrm{NO}_{x}\right)$ emitted during combustion reactions are environmental hazards as they create problems such as acid rain and depletion of ozone in the stratosphere. To develop a low $\mathrm{NO}_{x}$ combustor, a better understanding of the formation of $\mathrm{NO}_{x}$ in turbulent flames is essential. Although the route to $\mathrm{NO}_{x}$ formation and associated chemical kinetics are well-known, the interaction between the chemical reactions and turbulence is less well understood. An advanced combustion model is needed, which takes into account complex processes

\footnotetext{
${ }^{*}$ Corresponding author: School of Engineering, The Robert Gordon University, Schoolhill, Aberdeen, Aberdeenshire AB10 1FR, UK. email:M.Hossain@rgu.ac.uk
}

involving the detailed chemistry and non-equilibrium effect to be successful in predicting $\mathrm{NO}_{x}$ emission.

Turbulence-chemistry interaction has been a major focus of combustion researchers in the last few decades. Scalar variables such as temperature and concentrations of species are unique functions of a conserved scalar variable, a mixture fraction, in a turbulent reacting flame [1]. Once the mixture fraction and its fluctuations are known in a turbulent flame, the averaged scalar variable can be obtained by the integration of scalar variable functions with a presumed probability density distribution of the mixture fraction. This simplified fast chemistry-based approach is, however, inadequate to predict minor species such as $\mathrm{OH}$ and $\mathrm{O}$. Accurate prediction of $\mathrm{OH}$ and $\mathrm{O}$ is the first step in successful prediction of $\mathrm{NO}_{x}$. An advanced modelling approach is, therefore, required to predict $\mathrm{NO}_{x}$ emissions from a turbulent flame. The laminar flamelet model is one such advanced model. This model is based on the premise that a turbulent flame can be represented by an ensemble 
of 'laminar flamelets' stretched by turbulence $[2,3]$. In this modelling framework, a library of laminar flamelets is generated by solving transport equations on one-dimensional laminar flame configurations. Alternatively, a laminar flamelet equation on a mixture fraction space can be derived by a Crocco transformation [4]. Since the flamelet equations are solved for laminar flow, a detailed chemical reaction mechanism can be used for generating a flamelet library. The generated flamelet library is then linked to the reacting turbulent flow field through a variable known as the scalar dissipation rate. The effect of turbulence is thus decoupled from the chemistry with significant reduction of computational complexity. Conditional moment closure (CMC) [5] and transported probability density function (PDF) $[\mathbf{6}, 7]$ models are the other advanced models that have gained the attention of many researchers. The CMC model is based on a solution of conditional average equations of random reacting variables. The success of the CMC model depends largely on adequate modelling of the conditional moment of scalar variables in the Arrhenius reaction term. The transported PDF model does not require a model to represent the Arrhenius reaction term, but it requires a model to represent the mixing rate. The accuracy of the model depends on adequate modelling of the mixing rate. Though the model is theoretically more advanced, it still has shortcomings in predicting many of the features of turbulent flames such as local extinction [8].

Accurate prediction of the formation of oxides of nitrogen, especially NO, in turbulent non-premixed flames, has been a challenge to combustion modellers. There have been a number of recent studies in the formation of NO in both jet and bluff-body flames. Barlow et al. [9] reported a $\mathrm{H}_{2} / \mathrm{He}$ jet flame prediction of NO by using a transported PDF model. In their study, the transported PDF model produced better prediction of NO than a first-order CMC prediction. The same flame was also investigated by Kronenburg et al. [10] by using a second-order CMC model. They reported good prediction for NO. Roomina and Bilger [11] reported a first-order $\mathrm{CMC}$ study of a $\mathrm{CH}_{4} /$ air jet flame with reasonable accuracy for NO prediction. Mahmud et al. [12] reported an experimental and computational study of a $\mathrm{CH}_{4}$ jet flame. Their calculation by using a mixedness-reactedness flamelet model showed large overprediction of NO in the fuel-rich zone. Hossain and Malalasekera [13] reported the prediction of $\mathrm{NO}$ in a bluff-body $\mathrm{CH}_{4} / \mathrm{H}_{2}$ flame by using a steady laminar flamelet model. Their prediction suffered from accounting only for thermal route and showed large underprediction of the NO level. Kim and Huh [14] reported a first-order CMC modelling study of the same bluff-body flame by using Miller-Bowman, and GRI 2.11 and 3.0 mechanisms. Their simulation showed that the GRI 2.11 and Miller-Bowman mechanism yielded reasonable agreement with NO measurement. However, the GRI 3.0 produced large overprediction. Sreedhara and Huh [15] compared first- and second-order CMC model for the same bluffbody flame. They reported that the second-order CMC model improved the NO prediction, but still showed considerable overprediction.

The same bluff-body flame has been studied numerically by a number of researchers focusing on turbulence model. Dally et al. [16] reported simulation results obtained by using the standard and a modified $k-\varepsilon$ and Reynolds stress models. The main focus of their work was on the prediction of flow field, and both the $k-\varepsilon$ and Reynolds stress models in the standard form failed to predict the flow field accurately. The value of the turbulence model constant of $C_{\varepsilon 1}=1.6$ was proposed to improve the prediction of flow field. Merci et al. [17] applied a new cubic nonlinear eddy viscosity turbulence model to predict this flame. Their prediction showed that improvements in flow field prediction by using the new cubic model was only modest. Li et al. [18] investigated this flame by using various differential Reynolds stress models (DRSMs). They reported that all the differential stress models in the standard form failed to reproduce the mean velocity, velocity fluctuations, mean mixture fraction, and its variances. Modification of turbulence model constant led to minor improvements of the mean mixture fraction and variance profiles in upstream locations. However, the mean mixture fraction profiles were severely underpredicted at downstream locations. Yan et al. [19] provided a turbulence model sensitivity study by using the standard $k-\varepsilon$ model, the explicit algebraic stress model, and the $k-\varepsilon$ model with varied anisotropy parameters. Their study provided a very good prediction of mixture fraction profiles at upstream locations, though there was slight overprediction near the centre-line. The mixture fraction profiles were underpredicted at downstream locations. The prediction of mixture fraction variances as well as velocity fluctuations was poor. This bluff-body flame has also been studied by using large eddy simulation (LES) turbulence models $[20,21]$. The LES model calculation failed to predict the flow field in the farfield in Kempf et al.'s study [20]. However, Raman and Pitsch [21] provided a much better prediction by using a recursive filter-refinement procedure (RFRP) for LES. It is noteworthy that almost all of the approaches mentioned above needed modifications to the standard value of the model constants to provide a good prediction.

This article reports a numerical modelling study of the detailed structure of a $\mathrm{CH}_{4} / \mathrm{H}_{2}$ bluff-body flame. The predictions from the laminar flamelet model with Peters, GRI 2.11, GRI 3.0, and San Diego chemical mechanisms have been compared with the well-known Sydney bluff-body HM1 flame data [22]. The turbulent feature of the flame has been captured through a Reynolds stress transport (RST) model. 
Previous studies [16-21] have shown that the $k-\varepsilon$ model is not accurate enough to capture all the turbulence features in this flame, whereas the LES model is more demanding on computing resources without providing much improvement in the prediction. The Reynolds stress model, therefore, provides a good compromise between accuracy and computing resources.

\section{MATHEMATICAL MODEL}

\subsection{Thermofluids}

Reynolds averaged Navier-Stokes equations in conjunction with equations pertaining to the turbulence and combustion models have been solved by using an in-house finite-volume code. A brief description of the relevant governing equations and the modelling concept is presented here.

Overall mass continuity equation

$$
\frac{\partial \bar{\rho} \tilde{u}_{j}}{\partial x_{j}}=0
$$

Momentum conservation equation

$$
\frac{\partial}{\partial x_{j}}\left(\bar{\rho} \tilde{u}_{j} \tilde{u}_{i}\right)=-\frac{\partial \bar{P}}{\partial x_{i}}-\frac{\partial}{\partial x_{j}}\left(\rho \overline{u_{i}^{\prime \prime} u_{j}^{\prime \prime}}\right)
$$

The term $\rho \overline{u_{i}^{\prime \prime} u_{j}^{\prime \prime}}$ represents turbulent or Reynolds stresses. In the present study, this term was obtained from a RST model.

\subsection{Reynolds stress turbulence closure}

The RST model adopted in the present study is essentially the model proposed by Launder et al. [23], but with minor modifications. The model involves solving modelled partial differential equations for normal stresses and shear stress. The equations governing the transport of Reynolds stresses are given in Cartesian tensor notation as

$$
\frac{\partial}{\partial x_{k}}\left(\tilde{u}_{k} \rho \overline{u_{i}^{\prime \prime} u_{j}^{\prime \prime}}\right)=D_{i j}^{v}+D_{i j}^{\mathrm{T}}+D_{i j}^{\mathrm{P}}+P_{i j}+\Phi_{i j}-\bar{\rho} \tilde{\varepsilon}_{i j}
$$

The term on the left-hand side represents convective transport of the Reynolds stresses whereas the first three terms on the right-hand side represent molecular, turbulent, and pressure diffusion followed by production by shear, pressure-strain term and, finally, stress dissipation. For high Reynolds number flows, which are of interest in the present study, molecular diffusion is negligible and hence neglected. The pressure transport is considered to be much smaller than velocity transport, and hence pressure diffusion has been neglected as well. In the context of the present problem, the body force and production by rotation are not pertinent, and hence not considered in the transport equation.

Turbulent diffusion has been modelled by using the simple gradient diffusion hypothesis [24]

$$
D_{i j}^{\mathrm{T}}=-\frac{\partial}{\partial x_{k}}\left(\mu_{\mathrm{T}} \frac{\partial \overline{u_{i}^{\prime \prime} u_{j}^{\prime \prime}}}{\partial x_{k}}\right)
$$

Production by shear has been subjected to exact treatment and is given by

$$
P_{i j}=-\left(\rho \overline{u_{j}^{\prime \prime} u_{k}^{\prime \prime}} \frac{\partial \tilde{u}_{i}}{\partial x_{k}}+\rho \overline{u_{i}^{\prime \prime} u_{k}^{\prime \prime}} \frac{\partial \tilde{u}_{j}}{\partial x_{k}}\right)
$$

Pressure strain rate term is a combination of conventional Rotta's 'slow' or 'return-to-isotropy' term $\Phi_{i j 1}$ and a 'rapid' pressure strain term $\Phi_{i j 2}$ modelled according to isotropization of production proposal of Naot et al. [25]

$$
\begin{aligned}
\Phi_{i j}=\Phi_{i j 1}+\Phi_{i j 2}= & -C_{1} \bar{\rho} \frac{\tilde{\varepsilon}}{\tilde{k}}\left(\overline{u_{i}^{\prime \prime} u_{j}^{\prime \prime}}-\frac{2}{3} \delta_{i j} \tilde{k}\right) \\
& -C_{2} \bar{\rho}\left(P_{i j}-\frac{1}{3} \delta_{i j} P_{k k}\right)
\end{aligned}
$$

The model constants $C_{1}$ and $C_{2}$ are given the values of 1.8 and 0.6 , respectively.

The dissipation rate term has been modelled by using the local isotropy hypothesis of Kolmogorov, which is pertinent to high Reynolds number flows

$$
\tilde{\varepsilon}_{i j}=\frac{2}{3} \bar{\rho} \tilde{\varepsilon} \delta_{i j}
$$

The turbulent dissipation rate $\tilde{\varepsilon}$ is obtained by solving its transport equation

$$
\frac{\partial}{\partial x_{k}}\left(\bar{\rho} \tilde{u}_{i} \tilde{\varepsilon}\right)=\frac{\partial}{\partial x_{k}}\left(\frac{\mu_{\mathrm{T}}}{\sigma_{\varepsilon}} \frac{\partial \tilde{\varepsilon}}{\partial x_{k}}\right)+C_{\varepsilon 1} \frac{\tilde{\varepsilon}}{\tilde{k}} P_{k k}-C_{\varepsilon 2} \bar{\rho} \frac{\tilde{\varepsilon}^{2}}{\tilde{k}}
$$

where the rate of production of turbulent kinetic energy $P_{k}=0.5 P_{k k}$. The model constants take the following values: $C_{\varepsilon 1}=1.6, C_{\varepsilon 2}=1.44$, and $\sigma_{\varepsilon}=1.3$. The standard value for the model constant $\mathrm{C}_{\varepsilon 1}, 1.4$, has been changed following the recommendation of Dally et al. [16]. The turbulent kinetic energy can be obtained from the summation of normal stresses. However, to facilitate stability while solving for Reynolds stresses, the turbulent kinetic energy has been obtained from the solution of its transport equation

$$
\frac{\partial}{\partial x_{k}}\left(\bar{\rho} \tilde{u}_{i} \tilde{k}\right)=\frac{\partial}{\partial x_{k}}\left(\frac{\mu_{\mathrm{T}}}{\sigma_{k}} \frac{\partial \tilde{k}}{\partial x_{k}}\right)+P_{k}-\bar{\rho} \tilde{\varepsilon}
$$

where the Prandtl number for turbulent kinetic energy $\sigma_{k}$ takes a value of 0.82 as suggested by Lien and Leschziner [24]. 
In equations (8) and (9), the turbulent fluxes have been modelled by using a simple gradient diffusion hypothesis. This practice has also been adopted for scalars pertinent to combustion modelling; for example the mean mixture fraction and mean NO mass fraction. Although the turbulent scalar fluxes could be solved by a procedure similar to that adopted for Reynolds stresses, which would then lead to a full second moment closure, such an effort would involve significantly high computational times, and hence the simple gradient diffusion hypothesis has been preferred.

\subsection{Laminar flamelet model of combustion}

In the present study, the interaction between turbulence and combustion has been handled by employing laminar flamelet model. Laminar flamelet modelling is a two-step process. In the first step, a flamelet library is created by solving flamelet equations that are derived from conservation equations of mass, momentum, species, and energy through a Crocco transformation [4]. In the second step, the mean scalar variables in a turbulent flame are computed in a computational fluid dynamics (CFD) code by using the generated flamelet library.

The flamelet profiles specify temperature, density, and species concentrations by the mixture fraction $\mathrm{Z}$ and the scalar dissipation rate at stoichiometric mixture fraction $\chi_{\mathrm{st}}$. For turbulent flames, the mean scalar variables are computed from the laminar flamelet relation of the mixture fraction and the scalar dissipation rate by integrating with a joint probability density function as

$$
\tilde{\phi}=\int_{0}^{1} \int_{0}^{\infty} \phi\left(Z ; \chi_{\mathrm{st}}\right) \tilde{P}\left(Z, \chi_{\mathrm{st}}\right) \mathrm{d} \chi_{\mathrm{st}} \mathrm{d} Z
$$

The assumption of statistical independence between mixture fraction and scalar dissipation rate leads to $\tilde{P}\left(Z, \chi_{\mathrm{st}}\right)=\tilde{P}(Z) \tilde{P}\left(\chi_{\mathrm{st}}\right)[\mathbf{2}]$.

The mean value of the scalar dissipation rate can be modelled as

$$
\tilde{\chi}=C_{\chi} \frac{\tilde{\varepsilon}}{\tilde{\kappa}} \tilde{Z}^{\prime \prime}{ }^{2}
$$

where $\tilde{k}$ and $\tilde{\varepsilon}$ are the mean turbulent kinetic energy and its dissipation rate, respectively, and $C_{\chi}$ is a constant set equal to 2.0 [2]. The distribution of the scalar dissipation rate $\tilde{P}\left(\chi_{\mathrm{st}}\right)$ is assumed to be log-normal and the standard deviation for the log-normal distribution of the scalar dissipation rate is set $\sigma_{\chi}^{2}=2.0$ [2].

\subsection{NO model}

The formation of NO is a slow process, which is kinetically rate-limited. Unlike other species, the mean value of NO cannot be obtained from the flamelet library by using equation (10). The concentration of NO is determined by solving its transport equation given by

$$
\frac{\partial}{\partial t}\left(\bar{\rho} \tilde{y}_{\mathrm{NO}}\right)+\frac{\partial}{\partial x_{k}}\left(\bar{\rho} \tilde{u}_{k} \tilde{y}_{\mathrm{NO}}\right)=\frac{\partial}{\partial x_{k}}\left(\frac{\mu_{t}}{\sigma_{N O}} \frac{\partial \tilde{y}_{\mathrm{NO}}}{\partial x_{k}}\right)+\bar{\rho} \tilde{\dot{\omega}}_{\mathrm{NO}}
$$

where the turbulent Prandtl number $\sigma_{\mathrm{NO}}$ has been considered to be 0.7. During the flamelet calculation, for a given scalar dissipation rate, the production rate of NO is calculated and tabulated along with other reactive scalars as a function of mixture fraction. The rate of production of NO in the flamelet library is then integrated with presumed PDFs to obtain the mean source term $\tilde{\tilde{\omega}}_{\mathrm{NO}}$

$$
\tilde{\dot{\omega}}_{\mathrm{NO}}=\int_{0}^{\infty} \int_{0}^{1} \dot{\omega}_{\mathrm{NO}}\left(Z ; \chi_{\mathrm{st}}\right) \tilde{P}(Z) \tilde{P}\left(\chi_{\mathrm{st}}\right) \mathrm{d} Z \mathrm{~d} \chi_{\mathrm{st}}
$$

\subsection{Flamelet library generation}

The flamelet library has been generated by using the FlameMaster code of Pitsch [26]. FlameMaster solves the governing flamelet equations on the mixture fraction space. The effect of differential diffusion of species and radiation heat loss has been neglected, and unity Lewis number and equal diffusivity for all the species has been assumed. Reaction mechanisms used for the generation of flamelets are: Peters [27], GRI 2.11 [28] and GRI 3.0 [29], and San Diego [30]. The Peters mechanism employs reduced chemistry, with 53 elementary reactions for hydro-carbon chemistry in conjunction with the three-step Zeldovich mechanism of thermal NO. The GRI 2.11 employs detailed chemistry for both hydro-carbon and nitrogen chemistry and consists of 277 reactions with 49 species. The GRI 3.0 mechanism is a successor to version 2.11 and comprises of 53 species with 325 elementary chemical reactions (hydro-carbon + nitrogen chemistry). Notable modifications include changes in $\mathrm{CH}$ kinetics, which are important for the prompt NO formation. The San Diego mechanism is relatively new and it has been developed along the similar lines as the GRI 2.11 and GRI 3.0. This mechanism comprises 52 species with 454 reactions, which including detailed nitrogen chemistry.

\subsection{Burner geometry}

The bluff-body burner used for the simulation was experimentally investigated by Dally et al. [31]. The burner has an outer diameter of $50 \mathrm{~mm}$ and a concentric jet diameter of $3.6 \mathrm{~mm}$. A wind tunnel with an exit cross-section of $254 \mathrm{~mm} \times 254 \mathrm{~mm}$ encloses the burner. A single point Raman/Rayleigh/laser 


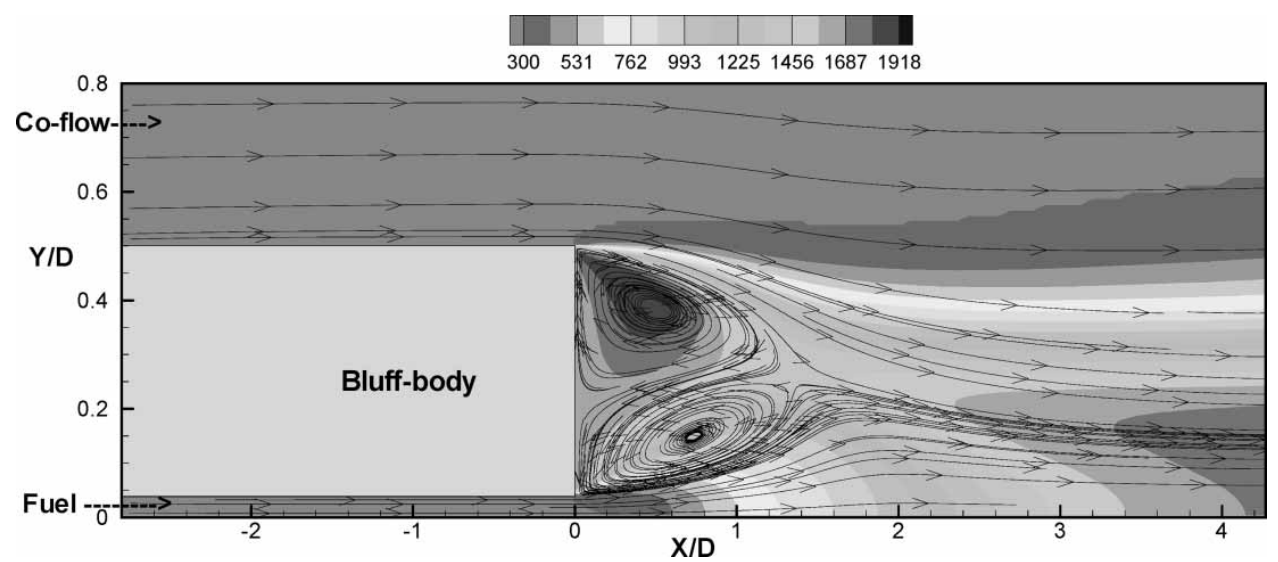

Fig. 1 Prediction of stream lines superimposed on mean temperature (K) contours in HM1 flame

induced fluorescence (LIF) technique has been used by Dally et al. [31] to measure temperature and the concentration of stable species $\mathrm{CO}_{2}, \mathrm{CO}$, $\mathrm{H}_{2} \mathrm{O}, \mathrm{H}_{2}$, and $\mathrm{N}_{2}$ as well as concentration of $\mathrm{OH}$ and $\mathrm{CO}$.

\subsection{Method of solution}

The laminar flamelet model has been applied to simulate a bluff-body stabilized $\mathrm{CH}_{4} / \mathrm{H}_{2}$ flame, known as HM1 flame, which was experimentally studied by
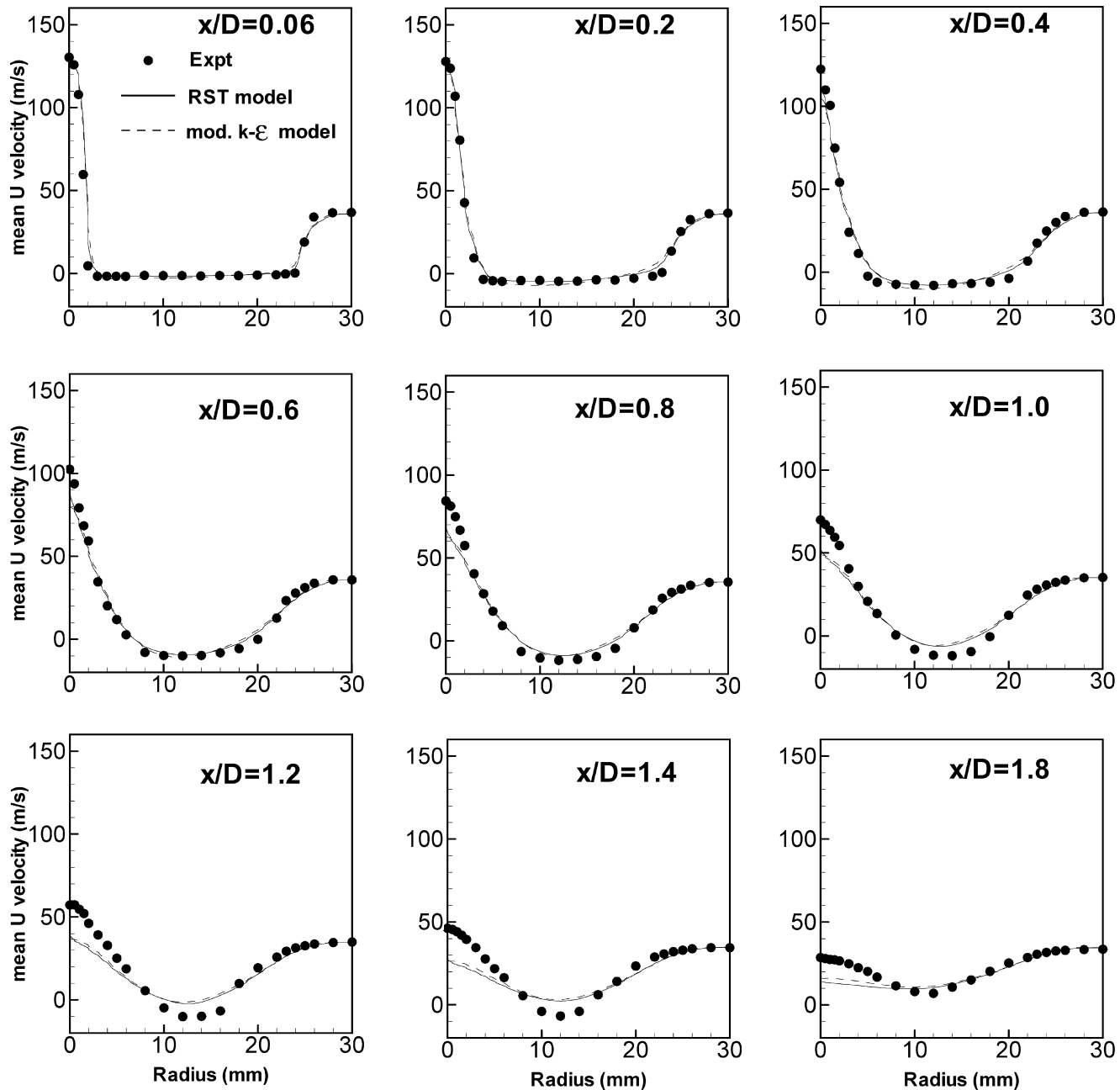

Fig. 2 Radial profiles of mean $U$ velocity (m/s) 
Dally et al. [31]. The flame operates at 50 per cent blowoff limit, with fuel and coflow streams at velocities of 118 and $40 \mathrm{~m} / \mathrm{s}$, respectively, and is devoid of any local extinction phenomenon. Hence, it is suitable for the application of laminar flamelet model. CFD simulation has been carried out by using an in-house finite-volume code with staggered structured grid arrangement in two-dimensional axisymmetric geometry. Governing equations in cylindrical coordinates have been discretized by using a hybrid scheme and the discretized algebraic equations have been solved by a line-by-line tri-diagonal matrix algorithm. Pressure-velocity coupling has been achieved by the SIMPLE algorithm. Mesh intensity is 162 nodes along axial direction and 111 nodes along radial direction. This mesh size has been chosen after carrying out a grid-independence study with two finer meshes and one coarser mesh.

The inlet of the domain has been extended by $3 \times$ bluff-body diameters upstream of the burner exit to develop flow prior to its entry into the reacting zone. At the outlet and symmetry, a zero normal gradient condition has been employed, whereas the bluff-body walls have been subjected to no-slip condition. Nearwall turbulence has been specified by using the universal log-law of the wall. Further, while employing the Reynolds stress model, the near-wall Reynolds stresses need to be treated. At the near-wall node $P$, normal stresses are derived from near-wall turbulent kinetic energy $\tilde{k}_{\mathrm{p}}$ from a closed set of algebraic equations (equation (14)). The near-wall Reynolds shear stress is obtained from the solution of its transport equation

$$
\begin{aligned}
& \left(\overline{u^{\prime \prime} u^{\prime \prime}}\right)_{\mathrm{p}}^{\mathrm{w}}=1.098 \tilde{k}_{\mathrm{p}}, \quad\left(\overline{v^{\prime \prime} v^{\prime \prime}}\right)_{\mathrm{p}}^{\mathrm{w}}=0.247 \tilde{k}_{\mathrm{p}}, \\
& \left(\overline{w^{\prime \prime} w^{\prime \prime}}\right)_{\mathrm{p}}^{\mathrm{w}}=0.655 \tilde{k}_{\mathrm{p}}
\end{aligned}
$$

\section{RESULTS AND DISCUSSIONS}

\subsection{Mixing and flow field}

Figure 1 shows the contour plot of stream function within the bluff-body combustor. Fuel enters the
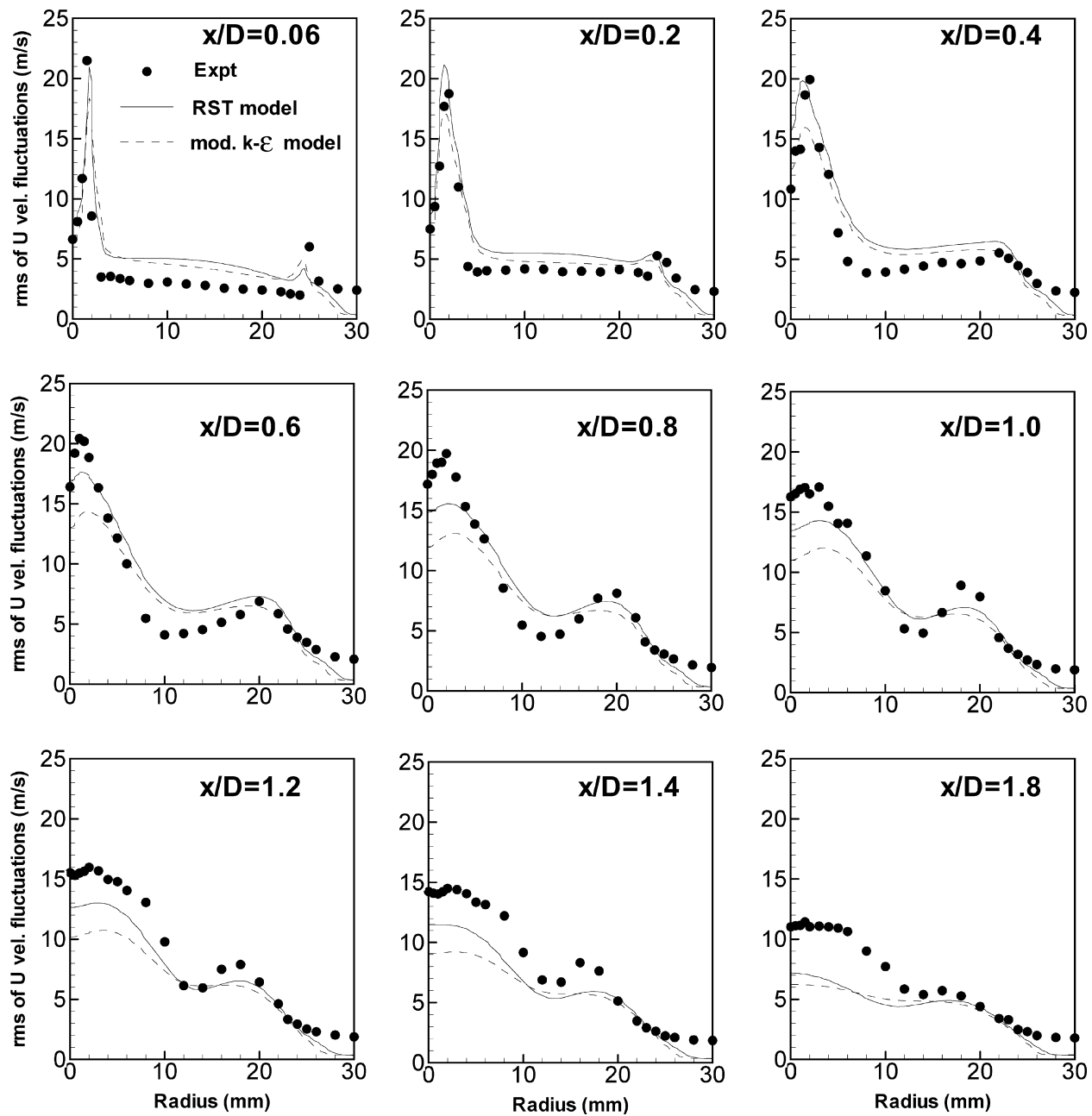

Fig. 3 Radial profiles of rms of $U$ velocity fluctuations (m/s) 
combustor through a central jet, whereas air enters through an annular space. As can be seen from Fig. 1, the flow is characterized by two counter-rotating vortices at the face of the bluff body. These vortices act to stabilize the flame. The length of the recirculation zone is predicted to be $x / D \sim 1.5$. Downstream of the recirculation zone is the neck zone where intense mixing takes place between the fuel jet and the coflow air. Further downstream, the flame expands like a jet flame.

The radial profiles of mean and root mean square (rms) of axial and radial velocity fluctuations for the related HMle flame, and laminar flamelet model predictions obtained in conjunction with a modified $k-\varepsilon$ model [16] have been shown in Figs 2 to 5. Agreement between the computations and experiment is generally good for the mean axial velocity, and there is a minor difference between the RST and modified $k-\varepsilon$ model. The rms of axial velocity fluctuation is underpredicted, especially near the axis, by both modified $k-\varepsilon$ and RST models. However, the RST model prediction is much better. Reasonable agreement is achieved for the mean and rms fluctuations of radial velocity.

\subsection{Thermo-chemical properties}

Figure 6 shows the radial mean mixture fraction profiles at different axial locations. Agreement between the prediction and measurement is good except at $x / D=1.8$ and $x / D=2.4$, where the computed results show minor underprediction in the mean mixture fraction profiles. Its prediction at downstream locations $(x / D=1.8$ and $x / D=2.4)$ has been proved to be challenging. Previous studies by using various DRSMs [18], non-linear $k-\varepsilon$ model [19], and even LES [20], failed to predict accurately the mean mixture fraction profile at the farfield. The present study provides a much better agreement compared to previous studies of DRSMs [18]. The extended upstream flow domain seems to be the main contributor for achieving better prediction. It provides realistic development of coflow before it enters the combustor and brings significant improvement of mixing in the outer shear layer. Using a RFRP for LES, Raman and Pitsch [21] have also shown that LES is capable of predicting downstream mixing field, provided the large-scale mixing in the outer shear layer is adequately resolved through reliable coflow
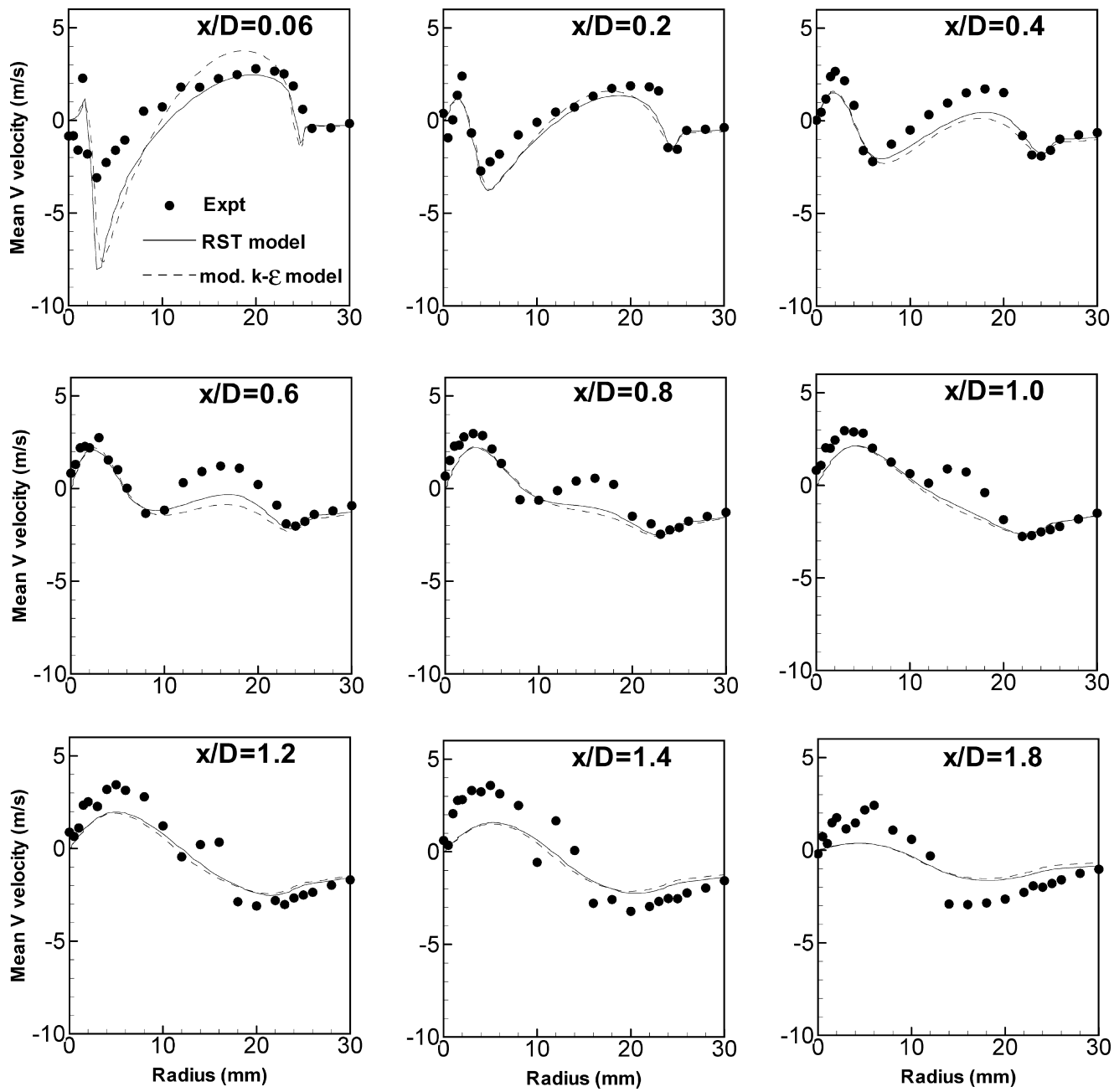

Fig. 4 Radial profiles of mean $V$ velocity (m/s) 
boundary conditions. Further study is undoubtedly needed to resolve the boundary conditions issue in the coflow to achieve accurate prediction.

The radial profiles of rms of mixture fraction fluctuations are shown in Fig. 7. Agreement between computation and measurement is not as good as for the mean mixture fraction. However, the present study provided a much better agreement compared to various previous studies [18-20].

Radial profiles of mean temperature are shown in Fig. 8. The mean temperature profiles are reasonably well-predicted and there is little difference among the reaction mechanisms of San Diego, GRI 2.11, and GRI 3.0. Peters mechanism produces small overprediction at all measuring stations. At $x / D=0.26$, the measured temperature in the outer vortex remains at $\sim 1650 \mathrm{~K}$, whereas the computational value shows a gradual increase of temperature from the inner to the outer edge of the outer vortex. Dally et al. [16] suggested that the experimental lower mean temperature at the edge of the outer shear layer was due the intermittent local extinction due to higher shear. However, Kuan and Lindstedt [32] suggested that the experimental probe might not adequately resolve the edge of the outer shear layer. Moreover, the uncertainty in the coflow boundary condition has a profound effect on the simulation result at the edge of the outer vortex close to the bluff-body face. These uncertainties discussed above have also resulted in bimodal prediction of $\mathrm{CO}_{2}$ (Fig. 10) and the overprediction of OH (Fig. 12) at $x / D=0.26$. Figures 9 and 10 present the radial profiles of mass fraction of $\mathrm{H}_{2} \mathrm{O}$ and $\mathrm{CO}_{2}$, respectively. When the prediction of mass fraction of $\mathrm{H}_{2} \mathrm{O}$ is very good, the prediction of $\mathrm{CO}_{2}$ is not as good especially at the farfield.

Figure 11 shows the mean CO profiles at different axial locations. The GRI 2.11, GRI 3.0, and San Diego mechanisms reproduce the $\mathrm{CO}$ profile reasonably well in the nearfield $(x / D<0.9)$ and are close to each other, while the Peters mechanism consistently predicts a lower CO level at all locations. This lower estimation of $\mathrm{CO}$ by Peters mechanism is consistent with the
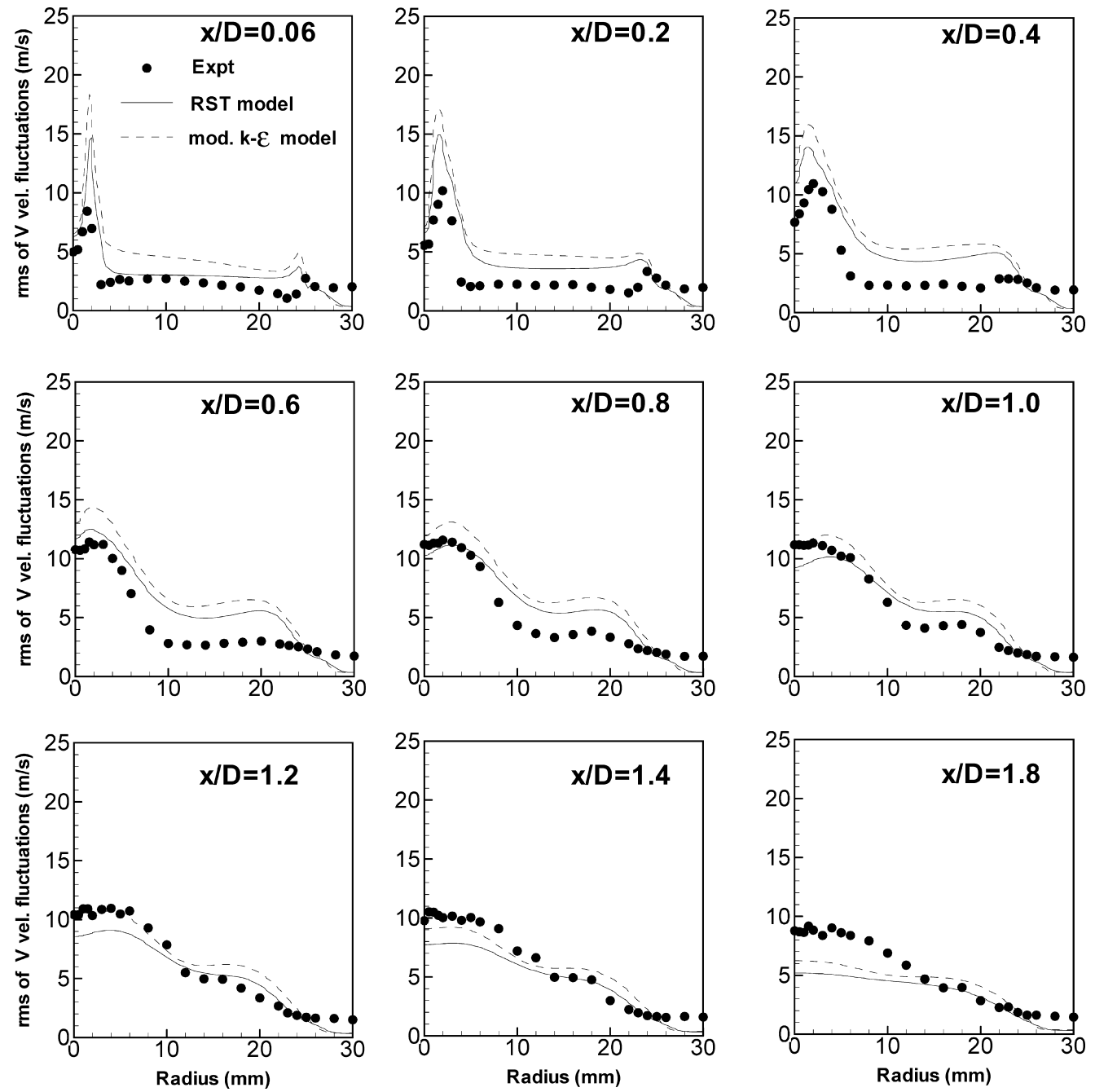

Fig. 5 Radial profiles of rms of $V$ velocity fluctuations (m/s) 

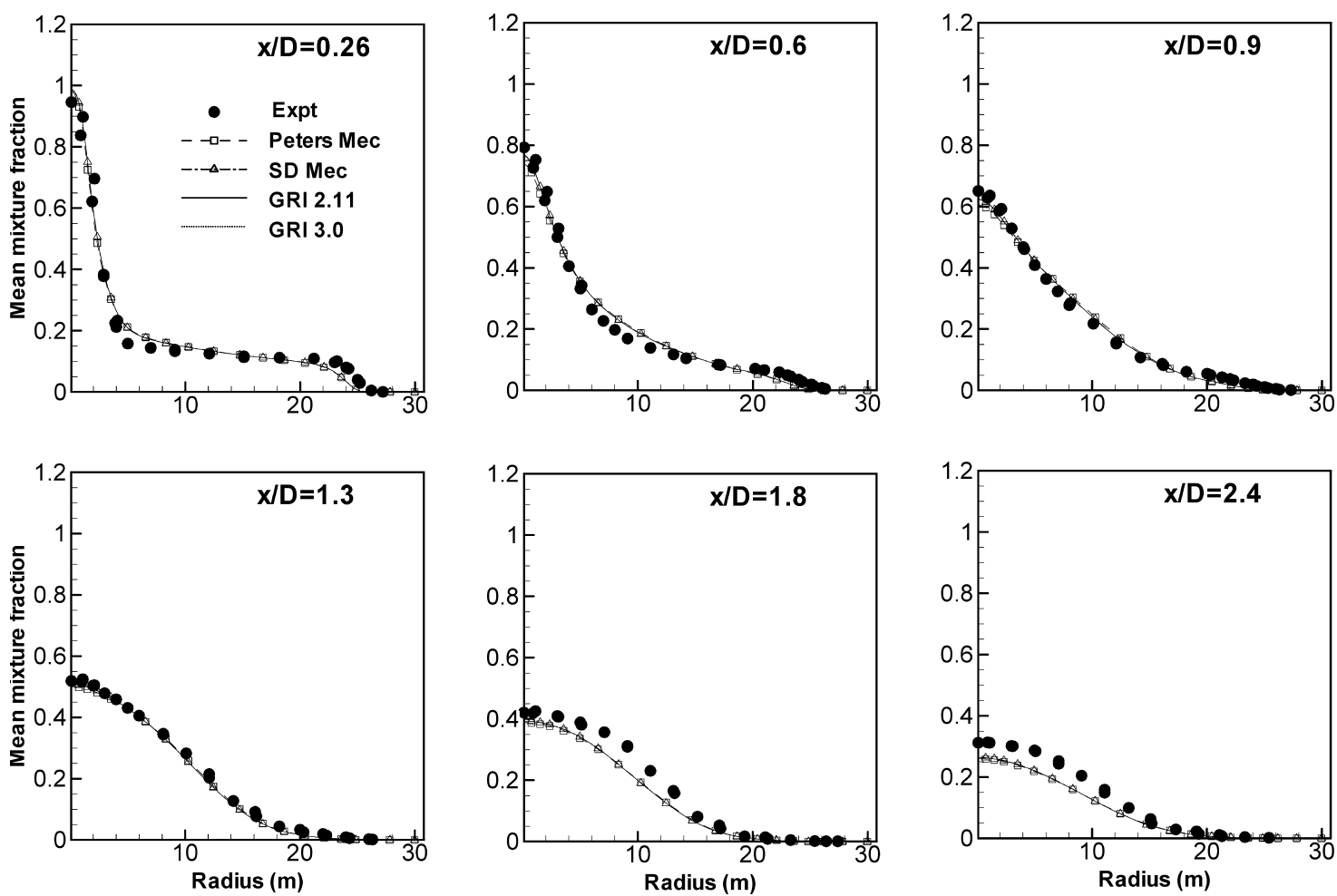

Fig. 6 Radial profiles of mean mixture fraction
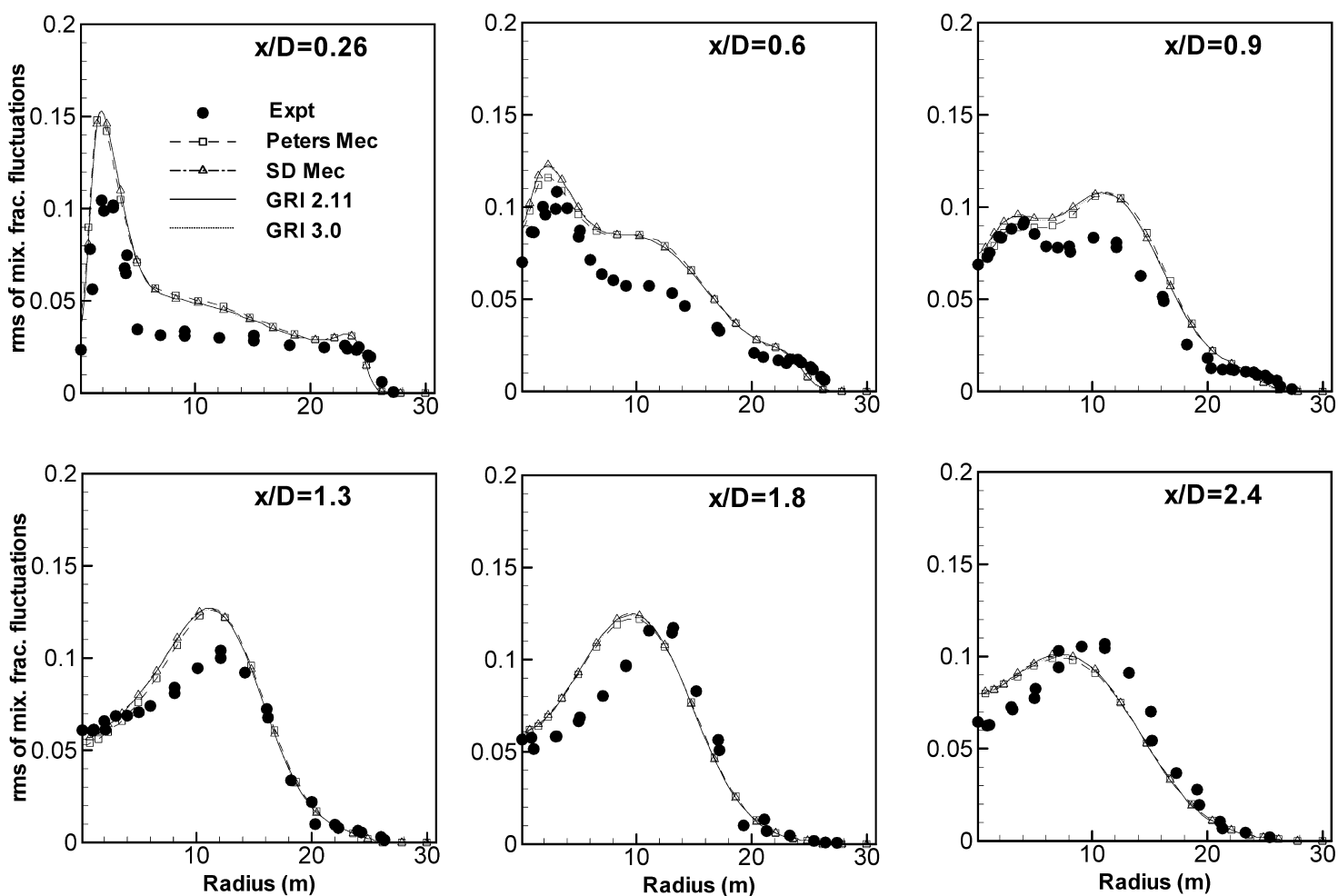

Fig. 7 Radial profiles of rms of mixture fraction fluctuations 
overprediction of $\mathrm{CO}_{2}$ level compared to other reaction mechanisms (Fig. 10). As explained earlier, the uncertainty in the coflow boundary condition has effected the prediction of the farfied flow field and this also resulted in the discrepancy of CO prediction in the farfield.
Mean mass fraction profiles of $\mathrm{OH}$ are shown in Fig. 12. Except at $x / D=0.26$, the $\mathrm{OH}$ level is well reproduced in the simulation by all reaction mechanisms. At $x / D=0.26$, the $\mathrm{OH}$ level is severely underpredicted. As explained above, the reaction zone at the outer shear layer may not be adequately resolved in the
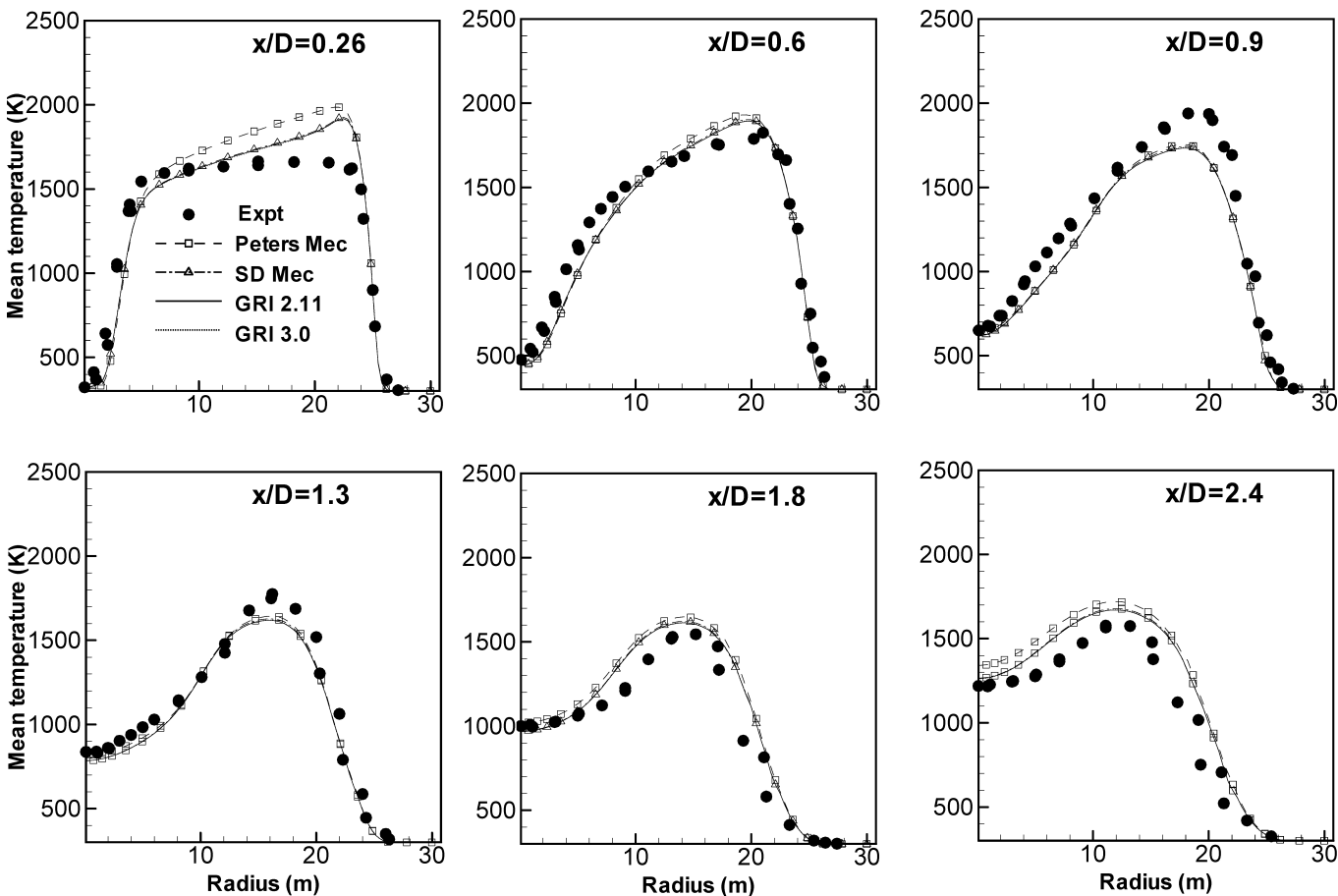

Fig. 8 Radial profiles of mean temperature (K)
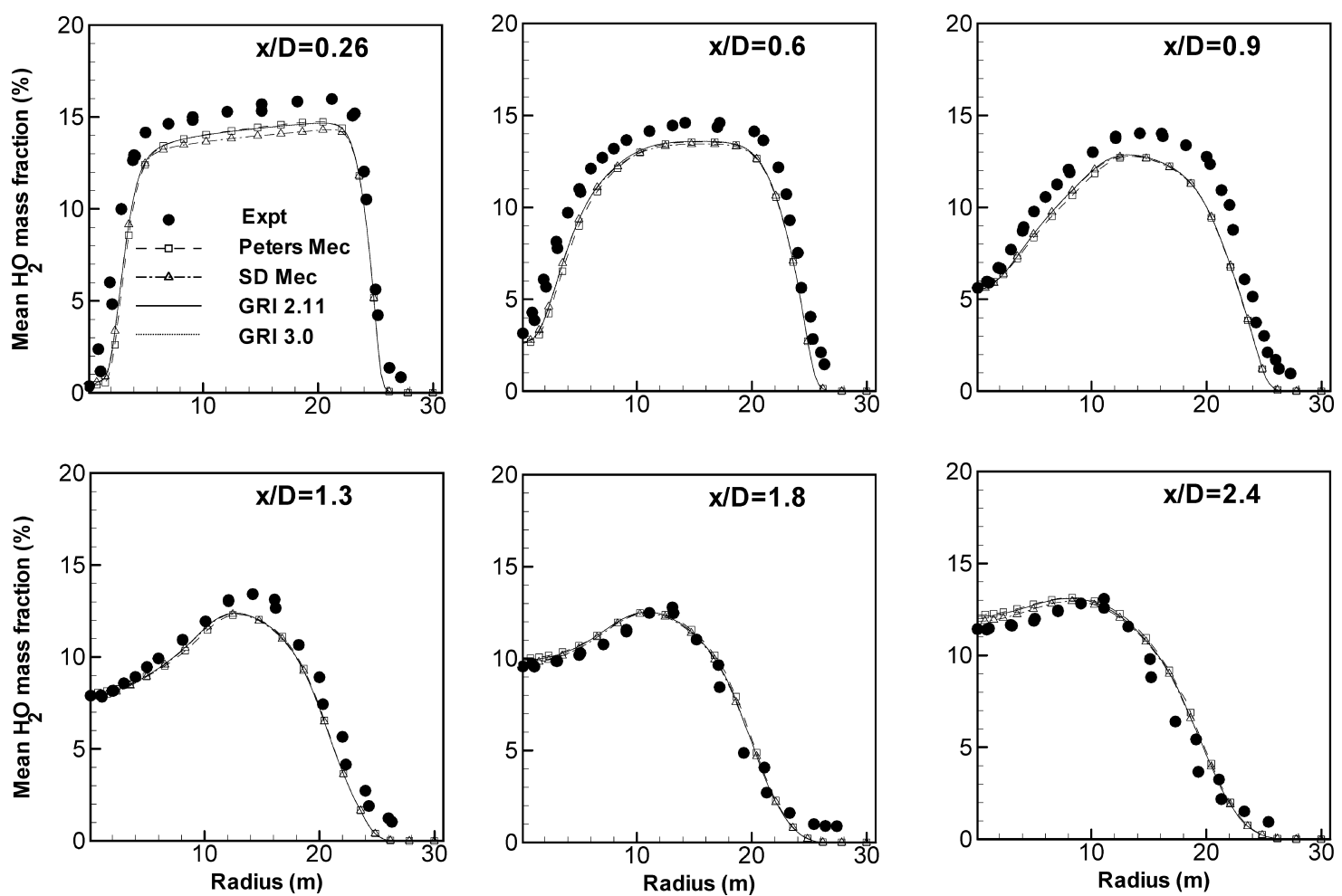

Fig. 9 Radial profiles of mean mass fraction of $\mathrm{H}_{2} \mathrm{O}$ 
experiment. This may partially explain the discrepancy between the experimental and numerical results. At $x / D=0.6$, the simulation predicts a wider reaction zone for $\mathrm{OH}$ compared to the measurement. All reaction mechanisms produced very similar prediction for $\mathrm{OH}$. Kim and Huh [14] also reported very similar prediction with GRI 2.11 and GRI 3.0 mechanisms. Compared to flamelet prediction of Kempf
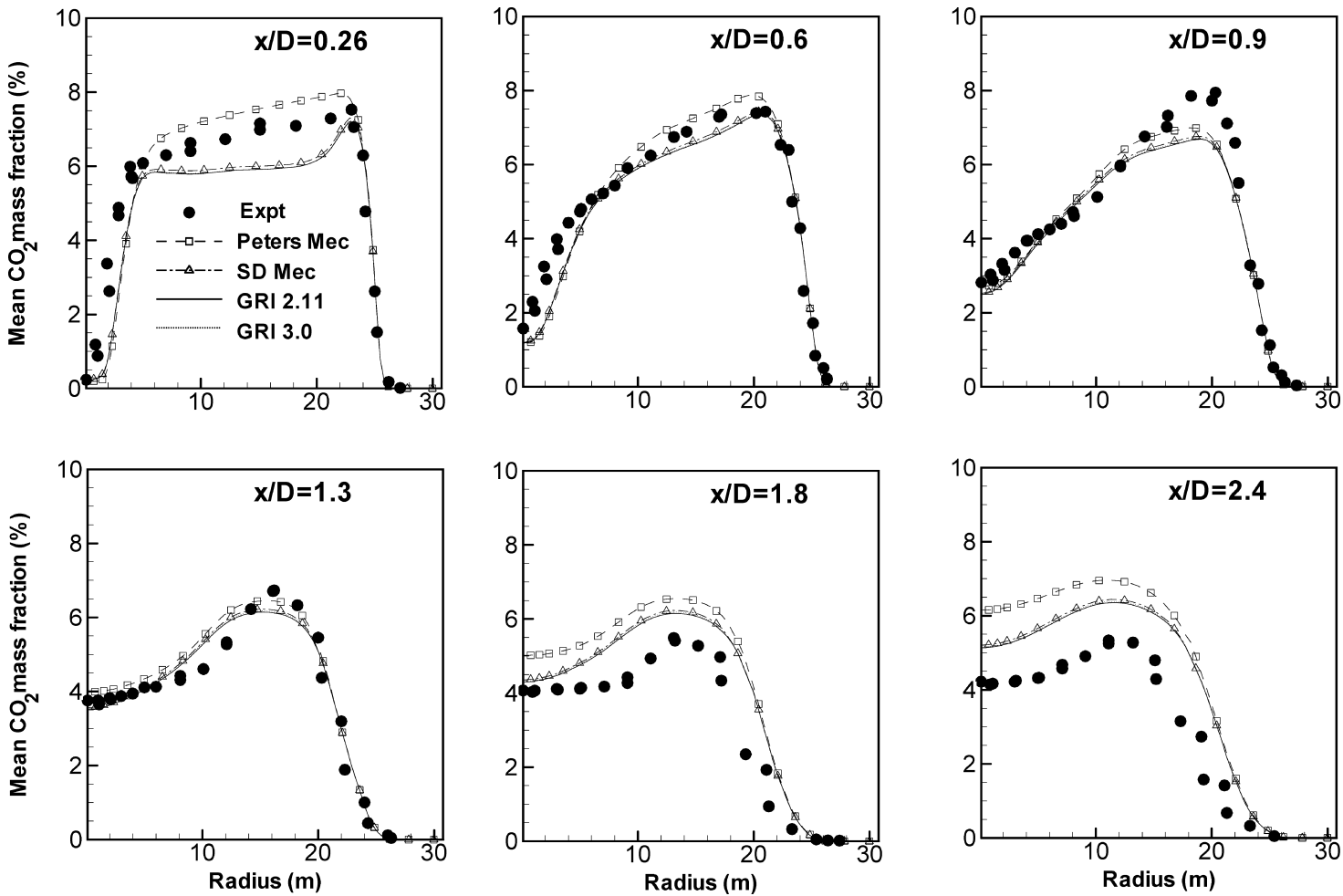

Fig. 10 Radial profiles of mean mass fraction of $\mathrm{CO}_{2}$
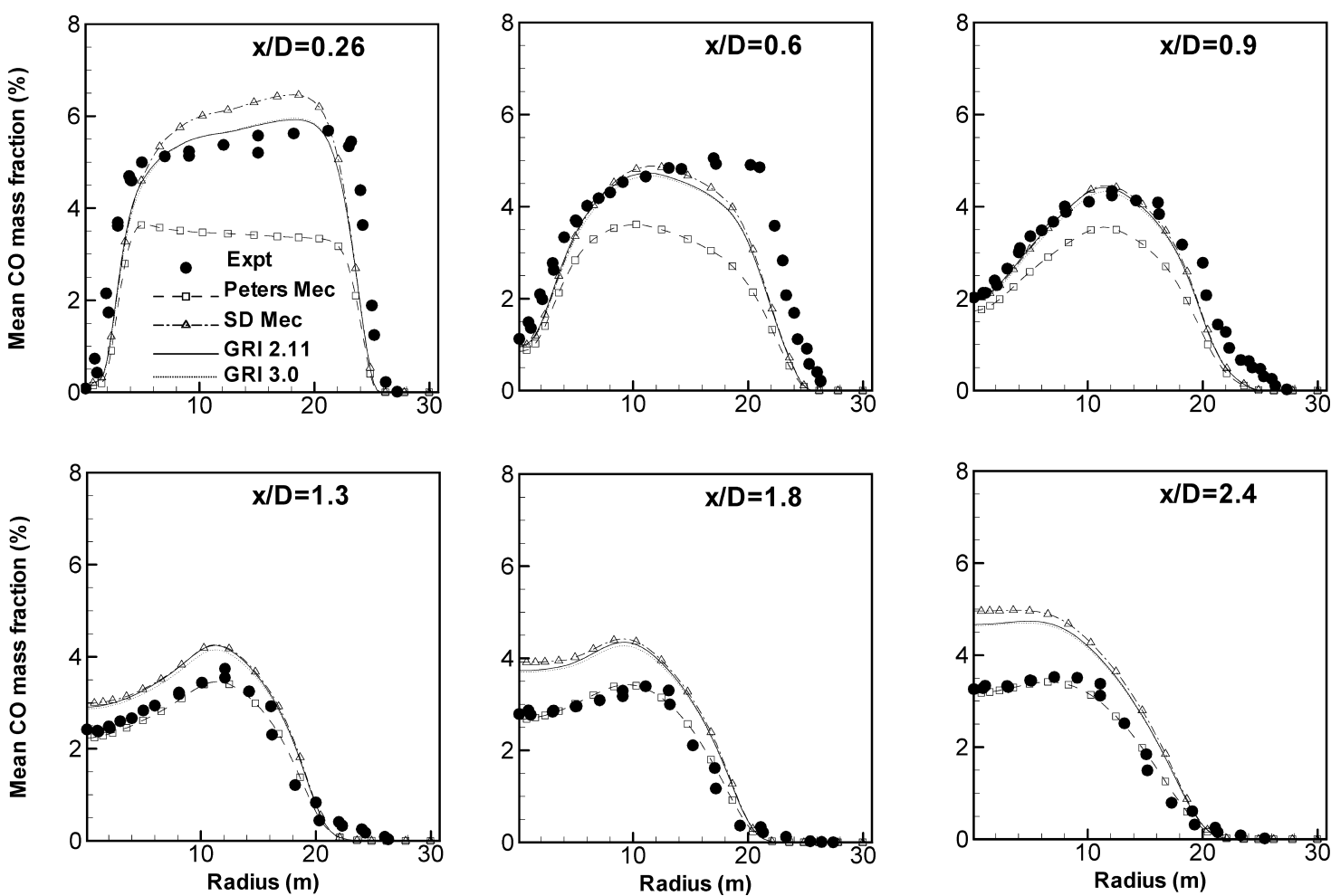

Fig. 11 Radial profiles of mean mass fraction of CO 
et al. [20] and CMC prediction of Sreedhara and Huh [15], the present study provided a better prediction, especially at downstream locations. Kempf et al. [20] reported a shift of the peak towards the axis of the combustor, whereas Sreedhara and Huh [15] reported a shift away from the axis of the combustor.

Figure 13 shows the radial profiles of NO at different axial locations. It is well-known that NO is
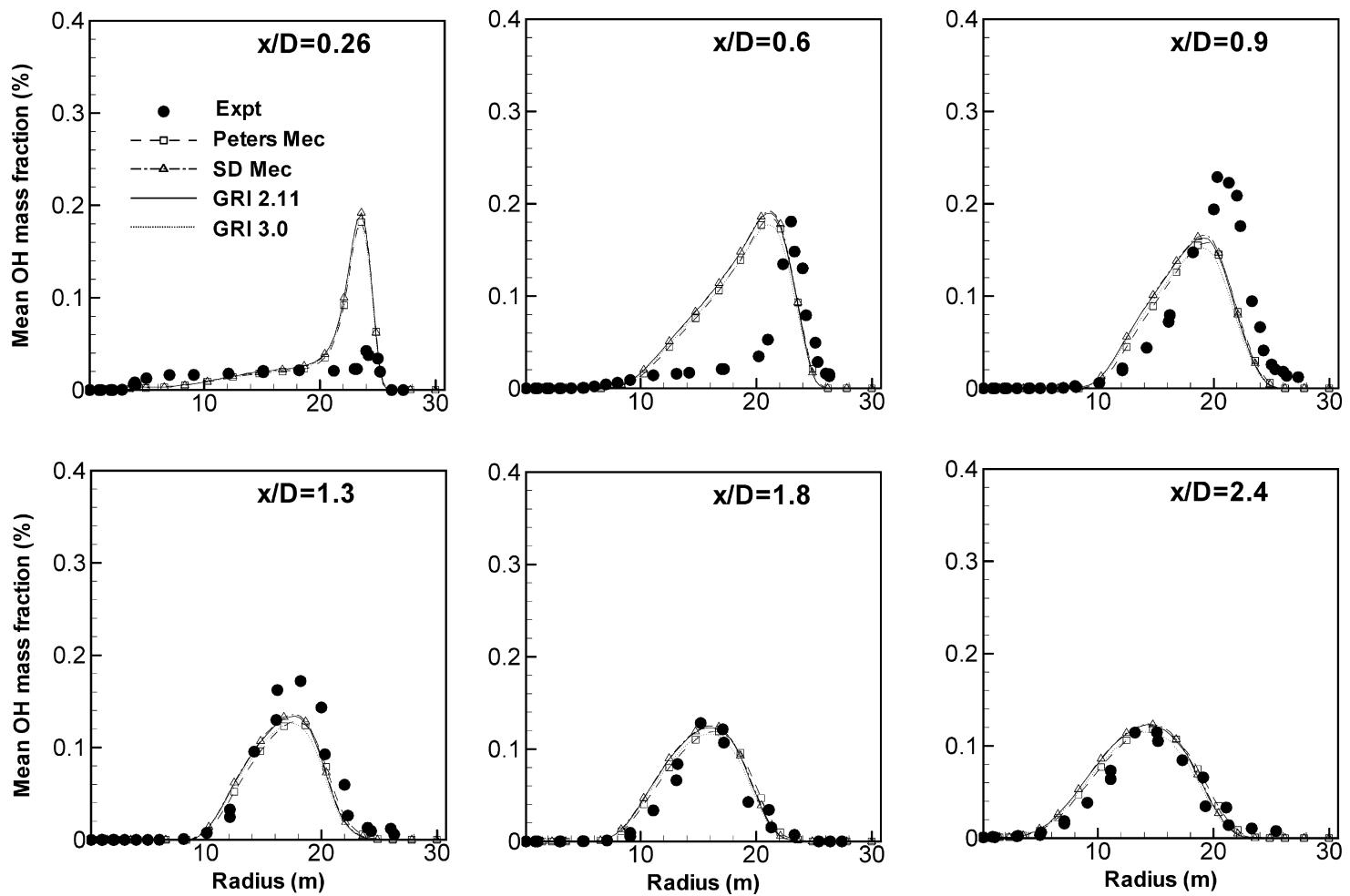

Fig. 12 Radial profiles of mean mass fraction of $\mathrm{OH}$
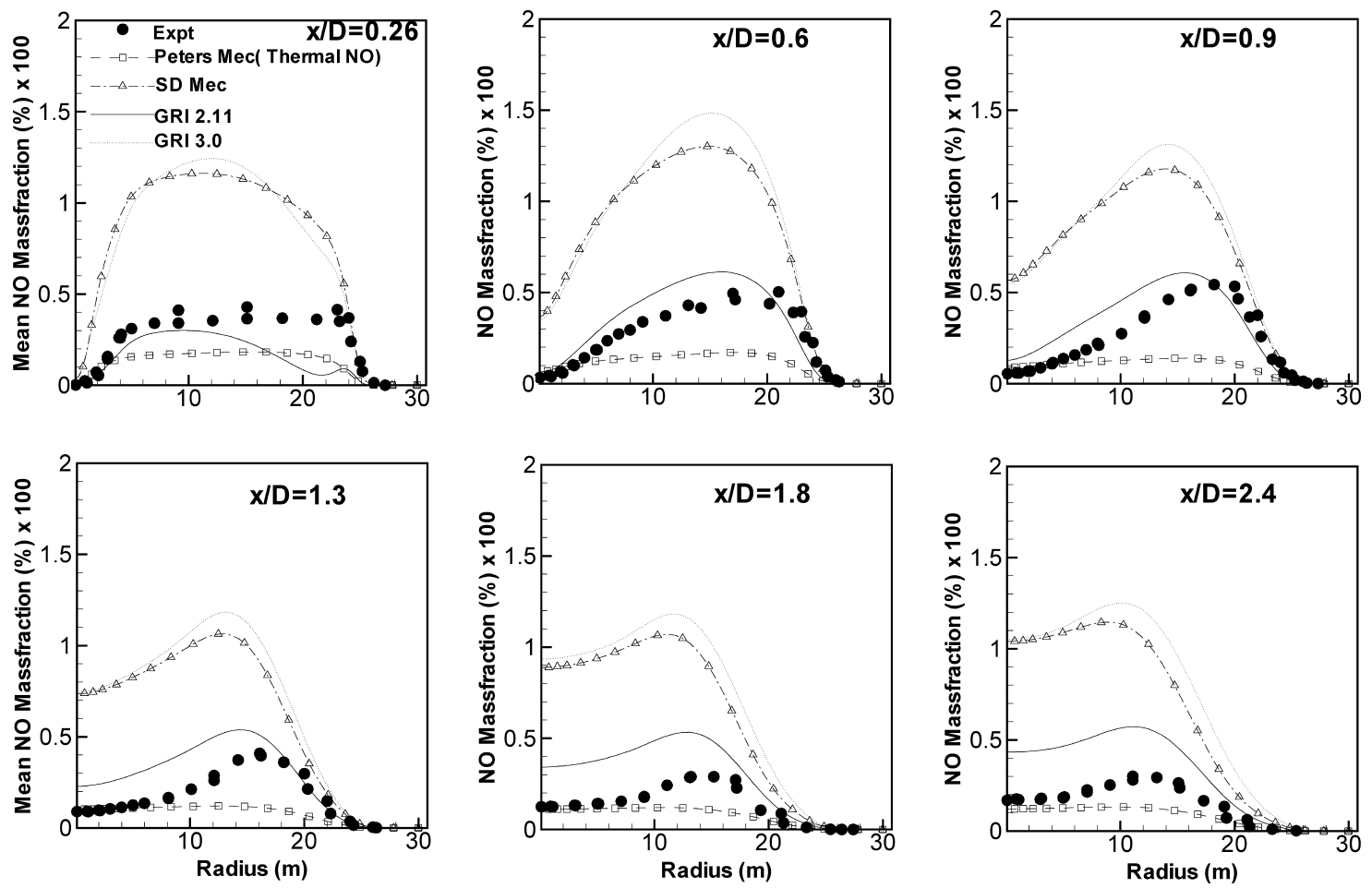

Fig. 13 Radial profiles of mean mass fraction of NO 
formed through (a) thermal or Zeldovich (b) $\mathrm{N}_{2} \mathrm{O}$ intermediate, and (c) Fenimore or prompt mechanisms. Thermal mechanism is important in the high-temperature region for both hydrocarbon and non-hydrocarbon flames. Prompt NO pathway is important for hydrocarbon flames in the rich zone, whereas $\mathrm{N}_{2} \mathrm{O}$ pathway is important in the lean zone. In the present study, only Peters mechanism includes the thermal mechanism and this leads to underprediction of NO by approximately 50 per cent. GRI 2.11 produces very good prediction of NO, especially in the nearfield. In the farfield, the GRI 2.11 mechanism overpredicts the NO level near the centre-line. The agreement achieved by the laminar flamelet model with GRI 2.11 is, however, much better compared to the first-order CMC model of Kim and Huh [14] and the second-order CMC model of Sreedhara and Huh [15]. In the present study, both San Diego and GRI 3.0 mechanisms overpredict the NO level by a large margin. Kim and Huh [14] also reported large overprediction of NO with the GRI 3.0 mechanism. They suggested that considerably higher rate coefficient for the principal prompt NO reaction $\mathrm{CH}+\mathrm{N}_{2}=\mathrm{N}+\mathrm{HCN}$ in GRI 3.0 mechanism is the primary reason for overprediction. Timescales for NO reactions are much slower than those for fuel reactions. This slower reaction rates for $\mathrm{NO}$ production is accounted for in the present simulation by solving a mass transport equation for NO with the source term obtained from the flamelet library. Despite this simple representation of kinetically controlled NO formation, the agreement achieved in the present study is very encouraging. Inclusion of an unsteady flamelet formulation has shown to improve the NO prediction over a steady-state flamelet formulation [33]. Another factor that could influence the overprediction of NO is the non-inclusion of radiation heat loss. Ravikanti et al. [34] have shown that although the effect of radiation is negligible on temperature and major species, the inclusion of radiation can improve NO prediction.

\section{CONCLUSIONS}

This report presents a numerical investigation of the detailed structure of a bluff body-stabilized $\mathrm{CH}_{4} / \mathrm{H}_{2}$ flame. The chemical reaction in the turbulent flame has been modelled by using a steady laminar flamelet model, whereas the turbulence has been represented by a Reynolds stress transport model. The computational domain included an extended upstream that allowed realistic development of turbulence at the entry to the combustor. A comparison of Peters, GRI 2.11, GRI 3.0, and San Diego reaction mechanisms has been made under the laminar flamelet modelling framework.

Good agreement has been achieved for the flowfield and thermo-chemical properties. Little difference has been observed among the reaction mechanisms for predicting mean temperature and major species distribution. However, a large difference has been observed in predicting mean NO distribution. The Peters mechanism, in conjunction with the thermal NO route, has produced large underprediction, whereas the GRI 3.0 and San Diego mechanism have produced large overprediction. The GRI 2.11 mechanism has yielded the overall best prediction for mean NO. The remaining discrepancy in the mean NO can be overcome by incorporating an unsteady laminar flamelet model and radiation effects.

\section{REFERENCES}

1 Jones, W. P. and Whitelaw, J. H. Calculations method for reacting turbulent flows: a review. Combust. Flame, 1982, 48, $1-26$.

2 Peters, N. Laminar flamelet models in nonpremixed turbulent combustion. Prog. Energy Combust. Sci., 1984, 10, 319-339.

3 Peters, N. Laminar flamelet concepts in turbulent combustion. Proc. Combus. Inst., 1986, 21, 1231-1250.

4 Bray, K. N. C. and Peters, N. Laminar flamelets in turbulent flames. In Turbulent reacting flows (Eds P. A. Libby and F. A. Williams), 1994, chapter 2, pp. 63-113 (Academic Press, London).

5 Bilger, R. W. Conditional moment closure for turbulent reacting flows. Phys. Fluids A, 1993, 5(2), 436-444.

6 Pope, S. B. PDF methods for turbulent reactive flows. Prog. Energy Combust. Sci., 1985, 11, 119-192.

7 Pope, S. B. Computations of turbulent combustion: progress and challenges. Proc. Combust. Inst., 1990, 23, 591-612.

8 Muradoglu, M., Liu, K., and Pope, S. B. PDF modelling of a bluff-body stabilized turbulent flame. Combust. Flame, 2003, 132, 115-137.

9 Barlow, R. S., Smith, N. S. A., Chen, J. Y., and Bilger, R.W. Nitric oxide formation in dilute hydrogen jet flames: isolation of the effects of radiation and turbulencechemistry submodels. Combust. Flame, 1999, 117, 4-31.

10 Kronenburg, A., Bilger, R. W., and Kent, J. H. Secondorder conditional moment closure for turbulent jet diffusion flames. Proc. Combust. Inst., 1998, 27, 1097-1104.

11 Roomina, M. A. and Bilger R. W. Conditional moment closure (CMC) predictions of a turbulent methane-air jet flame. Combust. Flame, 2001, 125, 1176-1195.

12 Mahmud, T., Sangha, S. K., Costa, M., and Santos, A. Experimental and computational study of a lifted, non-premixed turbulent free jet flame. Fuel, 2007, 86, 793-806.

13 Hossain, M. and Malalasekera, W. Modelling of a bluff body stabilised $\mathrm{CH}_{4} / \mathrm{H}_{2}$ flame based on a laminar flamelet model with emphasis on NO prediction. Proc. Instn Mech. Engrs, Part A: J. Power and Energy, 2005, 217, 201-210.

14 Kim, S. H. and Huh, K. Y. Use of the conditional moment closure model to predict NO formation in a turbulent $\mathrm{CH}_{4} / \mathrm{H}_{2}$ flame over a bluff-body. Combust. Flame, 2002, 130, 94-111. 
15 Sreedhara, S. and Huh, K. Y. Modeling of turbulent, two-dimensional nonpremixed $\mathrm{CH}_{4} / \mathrm{H}_{2}$ flame over a bluffbody using first- and second-order elliptic conditional moment closures. Combust. Flame, 2005, 142, 119-134.

16 Dally, B. B., Fletcher, D. E., and Masri, A. R. Flow and mixing fields of turbulent bluff-body jets and flames. Combust. Theory Model., 1998, 2, 193-219.

17 Merci, B., Dick, E., Vierendeels, J., Roekaerts, D., and Peeters, T. W. J. Application of a new cubic turbulence model to piloted and bluff-body diffusion flames. Combust. Flame, 2001, 126, 1533-1556.

18 Li, G., Naud, B., and Roekaerts, D. Numerical investigation of a bluff-body stabilised nonpremixed flame with differential Reynolds-stress models. Flow, Turbul. Combust., 2003, 70, 211-240.

19 Yan, J., Thiele, F., and Buffat, M. A turbulence model sensitivity study for $\mathrm{CH}_{4} / \mathrm{H}_{2}$ bluff-body stabilized flames. Flow, Turbul. Combust., 2004, 73, 1-24.

20 Kempf, A., Lindstedt, R. P., and Janicka, J. Large-eddy simulation of a bluff-body stabilised nonpremixed flame. Combust. Flame, 2006, 144, 170-189.

21 Raman, V. and Pitsch, H. Large-eddy simulation of a bluff-body-stabilised non-premixed flame using a recursive filter-refinement procedure. Combust. Flame, 2005, 142, 329-347.

22 Masri, A. R. Available from http://www.aeromech.usyd. edu.au/thermofluids/, accessed 11 December 2007.

23 Launder, B. E., Reece, G. J., and Rodi, W. Progress in the development of a Reynolds-stress turbulence closure. J. Fluid Mech., 1975, 68, 537-566.

24 Lien, F. S. and Leschziner, M. A. Assessment of turbulent-transport models including non-linear RNG eddy-viscosity formulation and second-moment closure for flow over a backward-facing step. Comput. Fluids., 1994, 23, 983-1004.

25 Naot, D., Shavit, A., and Wolfshtein, M. Interaction between components of the turbulent velocity correlation tensor. Isr. J. Technol., 1970, 8, 259-269.

26 Pitsch, H. A C ++ computer program for $0-\mathrm{D}$ and 1D laminar flame calculation. Available from http:// www.stanford.edu/group/pitsch/CES.html, accessed 11 December 2007.

27 Peters, N. Flame calculations with reduced mechanismsan outline. In Reduced kinetic mechanisms for applications in combustion systems (Eds N. Peters and B. Rogg), 1993, chapter 1, pp. 3-14 (Springer-Verlag, Berlin).

28 Available from http://diesel.me.berkeley.edu/ gri mech/new21/version21/text21.html, accessed 11 December 2007.

29 Available from http://www.me.berkeley.edu/gri-mech/ releases.html, accessed 11 December 2007.

30 Available from http://www-mae.ucsd.edu/ combustion/cermech/, accessed 11 December 2007.

31 Dally, B. B., Masri, A. R., Barlow, R. S., and Fiechtner, G. J. Instantaneous and mean compositional structure of a bluff-body stabilized nonpremixed flame. Combust. Flame, 1998, 114, 119-148.
32 Kuan, T. S. and Lindstedt, R. P. Transported probability density function modeling of a bluff-body stabilised turbulent flame. Proc. Combust. Inst., 2005, 30, 767-774.

33 Ravikanti, M., Odedra, A., and Malalasekera, W. Steady/unsteady flamelet modelling of $\mathrm{NO}_{x}$ in turbulent bluff-body stabilized non-premixed flames. In Work in progress abstracts of the 31st International Symposium on Combustion, 2006, p. 337 (The Combustion Institute, Pittsburgh).

34 Ravikanti, M., Malalasekera, W., Hossain, M., and Mahmud, T. Flamelet based $\mathrm{NO}_{x}$-radiation integrated modelling of turbulent non-premixed flame using Reynolds-stress closure. Flow, Turbul. Combust, 2008, 81, 301-319.

\section{APPENDIX}

\section{Notation}

\begin{tabular}{|c|c|}
\hline$C_{1}, C_{2}$ & $\begin{array}{l}\text { model constants in pressure strain } \\
\text { term }\end{array}$ \\
\hline$C_{\varepsilon 1}, C_{\varepsilon 2}$ & $\begin{array}{l}\text { model constants in dissipation rate } \\
\text { equation }\end{array}$ \\
\hline$D$ & diameter of the bluff body \\
\hline$D_{i j}$ & diffusivity \\
\hline$k$ & turbulent kinetic energy \\
\hline$P_{i j}$ & turbulence production by shear \\
\hline$P()$ & probability density function \\
\hline$u_{i}$ & velocity component \\
\hline$x_{i}$ & coordinate direction \\
\hline$y_{\mathrm{NO}}$ & mass fraction of $\mathrm{NO}$ \\
\hline$Z$ & mixture fraction \\
\hline$\delta_{i j}$ & Kronecker delta \\
\hline$\varepsilon$ & $\begin{array}{l}\text { dissipation rate of turbulent kinetic } \\
\text { energy }\end{array}$ \\
\hline$\mu_{t}$ & turbulent viscosity \\
\hline$\rho$ & density \\
\hline$\sigma$ & turbulent Prandtl number \\
\hline$\phi$ & scalar variables \\
\hline$\chi$ & scalar dissipation rate \\
\hline$\Phi_{i j}$ & pressure strain rate term \\
\hline$\dot{\omega}_{\mathrm{NO}}$ & NO production term \\
\hline
\end{tabular}

\section{Subscript}

st

stoichiometric

\section{Superscripts}

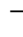

$\sim$

conventional ensemble average density-weighted ensemble average density-weighted fluctuation 